\title{
Corpo e mente sob violências: da dor ao silêncio, em Vidas secas
}

DOI: https://doi.org/10.22409/pragmatizes.v10i18.38897

\section{Paulo Cesar Silva de Oliveira ${ }^{1}$ Isabela Cristina Rodrigues Azevedo²}

Resumo: $\mathrm{O}$ artigo analisa distintas modalidades de violência a que são submetidos Fabiano, sinha Vitória e seus dois filhos meninos em Vidas secas, de Graciliano Ramos. Aponta-se a pobreza material, de vocabulário, não como resultado da animalização destes seres, mas como consequência das experiências traumáticas impostas. A partir das reflexões de Maria Cecília S. Minayo (2007), Michel Foucault (1987), Pierre Bourdieu (2012), Emmanuel Levinas (2016), Gayatri Spivak (2010), Walter Benjamin (1994) e Márcio Seligmann-Silva (2000), dentre outros, discutiremos o problema da violência no romance de Ramos, em alguns de seus múltiplos aspectos.

Palavras-chave:Violência na literatura; poder simbólico; trauma.

\section{Cuerpo y alma bajo violência: de ladolor al silencio en Vidas secas}

Resumen: El artículo analiza diferentes tipos de violencia a los que son sometidos Fabiano, sinha Vitória y los dos hijos, en la novela Vidas secas de Graciliano Ramos. Se señala la pobreza material del vocabulario, no como resultado de la animalización de los seres ficticios, sino como consecuencia de las experiencias traumáticas impuestas. Sobre la base de las reflexiones de Maria Cecília S. Minayo (2007), Michel Foucault (1987), Pierre Bourdieu (2012), Emmanuel Levinas (2016), Gayatri Spivak (2010), Walter Benjamin (1994) y Márcio Seligmann-Silva (2000) discutiremos el problema de la violencia en la novela de Ramos em algunos de sus múltiples aspectos.

Palabras clave: Violencia en la literatura; poder simbólico; trauma.

\section{Body and soul under violence: from pain to silence, in Vidas secas}

Abstract: The article analyzes different types of violence to which Fabiano, sinha Vitória and their two sons are subjected in Graciliano Ramos's novel Vidas secas. Their material poverty aligns with theirs carce vocabulary, not seen here a result of the animalization of these human beings, but as a consequence of imposed traumatic experiences. Based on the reflections of Maria Cecília S. Minayo (2007), Michel Foucault (1987), Pierre Bourdieu (2012), Emmanuel Levinas (2016), Gayatri Spivak

\footnotetext{
${ }^{1}$ Paulo Cesar Silva de Oliveira. Doutor em Letras pela UFRJ e Professor Adjunto de Teoria Literária da FFP/UERJ. Bolsista de Produtividade em Pesquisa do CNPq. Bolsista do Programa Prociência da FAPERJ, Brasil. Email: paulo.centrorio@uol.com.br - https://orcid.org/0000-0002-3710-4722

${ }^{2}$ Isabela Cristina Rodrigues Azevedo. Graduada em Letras pela Universidade Federal Fluminense. Mestranda do Programa de Pós-Graduação em Letras e Linguística da Universidade do Estado do Rio de Janeiro (UERJ), Brasil. E-mail: icrazevedo@gmail.com
} 
(2010), Walter Benjamin (1994) and Márcio Seligmann-Silva (2000) we will discuss the problem of violence in Ramos's novel focusing on some of its multiple aspects.

Keywords: Violence in literature; symbolic power; trauma.

\section{Corpo e mente sob violências: da dor ao silêncio, em Vidas secas}

A crítica literária comumente define as personagens de Vidas secas, de Graciliano Ramos (2013), como sujeitos animalizados, em contraste com a humanização da cadela Baleia, a que são equiparados. Nesta relação paradoxal, frequentemente se aponta a linguagem como um dos fatores de desumanização das personagens. De fato, Vidas secas pode ser considerado um drama sobre a linguagem. Como aponta Rui Mourão (2003, p. 117-135), em obra de 1969, o rompimento de Graciliano Ramos com os esquemas narrativos em primeira pessoa, empregados anteriormente a Vidas secas em Caetés, São Bernardo e Angústia se faz notar parcialmente na narrativa sobre Fabiano e sua família. Dizemos parcialmente, pois, como bem observou Wander Melo de Miranda, no "Prefácio" à terceira edição do livro de Mourão (2003, p. 9), "o resultado é uma "vitoriosa onisciência", a que o discurso indireto livre, sem dúvida, se encarrega de relativizar".

Ramos constrói um narrador que estaria supostamente "de fora" do fato narrado, como uma espécie de demiurgo. Este esquema narrativo revela mais do que uma estratégia artística: Fabiano e os seus não manejam a linguagem de forma a expressar a complexa rede de encobrimentos e impedimentos em que são apanhados. São formas de violência política, psicossociais a que são submetidos e o narrador cumpre 0 papel de porta-voz destes seres excluídos, falando "por" eles. Entretanto, porque não está à altura dos dramas vividos pelas personagens, o narrador os evoca indiretamente por meio de uma ilusória primeira pessoa. Isso é evidente quando analisamos essa estratégia narrativa de forma pragmática, como fez Castelar de Carvalho (1978, p. 16): “Dessa forma, aproximando o narrador do personagem, pode o Discurso 
Indireto Livre dar ao leitor a impressão de que ambos passam a falar em uníssono".

Gayatri Chakravorty Spivak, em Pode o subalterno falar? (2000, p. 3132), nos mostra que o termo "representação" pode ter o sentido de "falar-por", como na política; e de "representação", na arte ou na filosofia. Para Spivak, a teoria é apenas uma ação, daí o teórico não representar o oprimido, como se falasse por ele. No caso da representação literária em Vidas secas, há uma superposição de camadas que devemos considerar: Graciliano, autor-empírico, cria um narrador, que se transforma em autormodelo e que, por vezes, concede voz aos subalternos, mas na verdade, esse sujeito só entra no discurso por uma concessão do narrador heterodiegético, que manipula os discursos. Mesmo no caso das narrativas em primeira pessoa em que se ficcionaliza um sujeito subalterno, a voz deste sujeito é camuflada, visto que sua subalternidade é ficcionalizada e não real. Quando dizemos que Jorge Amado ou Graciliano Ramos, dois autores da década de 1930, "dão voz" aos marginalizados, não podemos esquecer que essa é uma falsa voz, visto que os subalternos não falam em seus textos, são neles representados. Isso interessa a Spivak, quando discute a produção de um "Outro" chancelado pela voz do intelectual, o que não quer dizer que devemos advogar a retirada do intelectual do jogo, mas que ele tenha consciência de sua responsabilidade institucional.

A reflexão de Spivak é especialmente importante para entendermos que, quando discutimos o problema da violência e do corpo, em Vidas secas, estamos transitando por um universo construído por um autor (Graciliano Ramos) que não participa dos eventos ficcionalizados, a não ser como testemunha que se solidariza com as personagens errantes que representa. Cabe ao crítico expor esses paradoxos no âmbito de uma economia ficcional que demanda reflexões que vão desde o papel do escritor-intelectual - aquele que se coloca "a favor" de uma determinada classe - ao resultado deste processo: a representação deste posicionamento na dupla articulação "falar-por" e "re-presentação".

A linguagem que reproduz a violência institucional, ou seja, a 
linguagem trágica que permeia 0 romance de Ramos nos dá conta destes meandros que tornam a tarefa do crítico indispensável. À escassez de linguagem de suas criaturas enclausuradas, acresce a violência institucional, reproduzida também pelas próprias personagens em seu cotidiano trágico. Fabiano, sinha Vitória e os dois filhos são afetados pela seca e pela região sem recursos, mas a reflexão de Ramos não se limita a um determinismo que explique de forma pragmática os processos violentos encenados. Precisamos expandir algumas questões apresentadas pelo romance para campos mais amplos de problematização, como a questão do corpo e a vigência do trauma. Ambas expõem a condição humana de homens brutos que, ficcionalizados, demandam o escrutínio do leitor crítico.

Em um texto de 1934, Emmanuel Levinas (2016), ao tratar da filosofia do hitlerismo, talvez tenha sido, senão um dos primeiros, um dos mais contundentes pensadores a tratar da questão da barbárie nazista no contexto de um processo de desumanização do homem. Levinas discutia as origens do mal no contexto de uma modernidade da promessa (leia-se uma modernidade europeia e norte-americana, basicamente) que tinha a mobilidade como norte, mas nos legou a barbárie do assassínio de milhões de seres humanos, com seus corpos confinados em campos de extermínio em massa. As reflexões pioneiras de Levinas nos auxiliarão em nossas hipóteses de trabalho e leitura de Vidas secas.

Levinas entende que o nazismo transformou a "força" em um universal, deslocando a perspectiva iluminista de uma "sociedade de iguais" para o ambiente de uma "sociedade de força" em que grupos dominantes subjugam os demais. Conforme bem resumiu Arnold I. Davidson (2016, p. 34), em sua leitura de Levinas:

Uma força engrandece a pessoa ou
a sociedade que a exerce. E
subordina os outros. Em vez de criar
uma sociedade de iguais, a
expansão da força, de uma força
enraizada na raça, cria um mundo de
senhores e escravos. Portanto,
enfrentamos um ideal "que traz ao
mesmo tempo sua forma própria de
universalização: a guerra, a
conquista".

Levinas propõe compreender o advento do fascismo através da questão do corpo, evitando as noções clássicas e europeias de homem. A 
partir da ascensão do nazismo, o corpo foi objeto não só de controle, mas de sistemático extermínio. Levinas nos dá ciência de que o corpo sempre foi compreendido como um estrangeiro habitando em nós; 0 dualismo eu $x$ corpo deve desaparecer, defende, para que possamos ser espíritos verdadeiramente livres. Talvez por isso - controle sistemático dos corpos, inclusive dos corpos exterminados, tenha sido um dos capítulos mais contundentes de nossa história moderna. Da promessa de mobilidade resultou uma realidade da clausura. Move-se, mas para onde? Esse é o primeiro grande acerto de Graciliano Ramos, em Vidas secas, ao representar a violência a que a família de despossuídos era exposta: problematizar o destino dos corpos que circulam por espaços claustrofóbicos em um tempo cíclico. A narrativa se inicia com o capítulo "Mudança" e se fecha com "Fuga". Esse aprisionamento em uma circularidade até permite a circulação dos corpos no espaço-tempo,porém agrilhoados nos esquemas de clausura que os impede de suplantar as limitações da matéria e do mundo circundante.

A personagem Fabiano até consegue suspeitar de suas limitações, que são as mesmas de seu corpo em/sem liberdade. Em "Cadeia", o aprisionamento físico se cola ao aprisionamento espiritual. Vítima da brutalidade do poder e de uma violência que ultrapassa a materialidade de seu corpo, Fabiano se revolta e pensa em retaliar, mas suas indignações esbarram na ideia de que há um poder maior que o regula: o governo. Sua prisão acontece após uma ida à feira da cidade para comprar mantimentos. Lá, ele percebe que é roubado no preço das mercadorias, no querosene adulterado com água, na cachaça igualmente aguada. Fabiano é chamado pelo soldado amarelo - espécie de metonímia da força e da violência institucionais - para um jogo de baralho em que perde todo o dinheiro e seu pagamento. Provocado mais tarde pelo soldado, acaba na cadeia, onde matura raiva e humilhação e pensa em vingança - que não consuma. Em determinado momento do capítulo, a consciência de seu 
agrilhoamento é assim descrita pelo narrador:

Agora Fabiano conseguia arranjar as ideias. O que o segurava era a família. Vivia preso como um novilho amarrado ao mourão, suportando ferro quente. Se não fosse isso, um soldado amarelo não lhe pisava o pé não. O que the amolecia o corpo era a lembrança da mulher e dos filhos. Sem aqueles cambões pesados, não envergaria o espinhaço não, sairia dali como onça e faria uma asneira. Carregaria a espingarda e daria um tiro de pé de pau no soldado amarelo. Não. O soldado amarelo era um infeliz que merece um tabefe com as costas da mão. Mataria os donos dele. Entraria num bando de cangaceiros e faria estrago nos homens que dirigiam 0 soldado amarelo. Não ficaria um para semente. Era a ideia que Ihe fervia a cabeça. Mas havia a mulher, havia os meninos, havia a cachorrinha (RAMOS, 2013, p. 37).

Essa passagem é determinante para nossa análise. Em primeiro lugar, porque o narrador, ao conceder voz a Fabiano, fala com e por ele, o que nos leva de volta ao problema da representação, que vimos com Spivak. Em segundo lugar, a consciência da desigualdade alcança um estatuto de quase revolta, de rebelião. Fabiano pensa em matar o soldado, mas logo aquiesce, após refletir sobre os verdadeiros donos do poder, de quem o soldado é apenas um emissário sem importância. As estruturas oligárquicas que perpetuam o estado de violência e injustiça são por ele consideradas a causa de sua humilhação. Fabiano namora, quase em delírio, com a revolta armada - ser um cangaceiro e exterminar os homens que dirigiam o soldado amarelo -, o que seria um patamar radical, próprio dos sujeitos que percebem a extensão do nível de aprisionamento de seus corpos. Do assujeitamento a uma ordem que o ultrapassa à transgressão violenta, Fabiano vai a extremos, questionando a animalização de seu corpo - ora se vê como um novilho amarrado ora como uma onça em acesso de fúria. Isso nos leva novamente ao texto de Levinas, quando o filósofo pensa a questão do corpo como essência do humano: "A essência do homem já não está na liberdade, e sim numa espécie de agrilhoamento.

Ser verdadeiramente si mesmo não é retomar seu voo por sobre as contingências, sempre estranhas à liberdade do Eu [...]". Tomar "consciência de nosso agrilhoamento original inelutável e único a nosso corpo; é, sobretudo, aceitar esse agrilhoamento, no entanto, para que se possa libertar o corpo e libertar-se das estruturas sociais" (LEVINAS, 2016, p. 63). 
Embora a articulação entre animal e homem não se dê de forma simplista, não é possível negar tal equiparação, algo que Antonio Candido já apontara. Afirmando que as personagens de Vidas secas continham uma "pureza" que thes dispensava "refinamento", Candido alinha subjetivamente as protagonistas da obra:

O matutar de Fabiano ou Sinhá Vitória não corrói o eu nem representa atividade excepcional. Por isso é equiparado ao cismar dos dois meninos e da cachorrinha, pois no primitivo, na criança e no animal a vida interior obedece outras leis, que o autor procura desvendar: não se opõe ao ato, mas nele se entrosa, imediatamente. Daí a pureza do livro, o impacto direto e comovente, não dispersado por qualquer artificioso refinamento (CANDIDO, 2006, p. 65).

Perceber o modo como os sujeitos são afetados pelo meio em que vivem é importante para pensarmos a subjetividade desses seres, contudo, a interferência do meio sobre os corpos e mentes não torna os sujeitos necessariamente desumanizados, mas sim feridos, 0 que explicaria o emudecimento frente à experiência traumática. Em face disso, cabe-nos analisar o modo como a obra é atravessada por uma série estrutural de violências. A pobreza a que são expostas as personagens; as lembranças da seca aliadas às marcas físicas e emocionais deixadas, bem como a imposição das autoridades, que atuam arbitrariamente, por serem hierarquicamente superiores na escala socioeconômica, corroboram para que o comportamento da família seja uma metáfora da condição subalterna. Cabe afirmar aqui, com base nos postulados de Michel Foucault (1987), que as personagens de Vidas secas são atravessadas pela violência estrutural, tal como a define Maria Cecília S. Minayo (2007), de que trataremos adiante. Há, então, a clara presença de um "poder simbólico" (BOURDIEU, 2012) que afeta diretamente a conjuntura social e existencial a que estão submetidos os sertanejos traumatizados pela dura realidade imposta.

Vidas secas (1938) narra a história de uma família composta por um homem, uma mulher, dois meninos e uma cachorra em extrema situação de miséria. É significativa a escolha do autor em nomear a única mulher protagonista por "sinha Vitória" e não "sinhá Vitória", acentuado tal como a norma requer. Ilma da Silva Rebello (2005), em seu artigo "As classes 
populares e as duras cavalgaduras da vida: uma leitura de Vidas secas, de Graciliano Ramos", aponta para as diferenças de sentido que atravessam a escolha do autor. Há na retirada do acento uma marca que simultaneamente é econômica, social e moral.

Constata-se que Graciliano Ramos preferiu "sinha" ao invés de "sinhá". Magalhães (2001: 120) expõe que nas Alagoas a palavra sinhá é usada para mulheres da classe dominante, esposas dos proprietários de terra e sinha para os pobres, casadas e dignas de respeito. Por isso, sinha Vitória (REBELLO, 2005, p. 8).

Sutilmente, não só a mulher, mas toda a família tem sua definição inscritana hierarquia política e social a que são expostos,assim como cada um de nós, invariavelmente. Embora sem recursos financeiros, Fabiano e os seus são pessoas de atitudes lícitas, "dignas", honestas. A informação fornecida por Magalhães ressignifica não só o nome próprio, que pode passar despercebido para um leitor menos atento: pobreza e honestidade são pares positivos naquela família, assim como os parâmetros de ética e moral que levam Fabiano, por exemplo, a submeter-se a humilhações ao longo da narrativa,em prol do bem comum dos seus.

Sem posses e sem escolhas, a família, após transitar em busca de nova terra, aloca-se em uma fazenda para viver à mercê da exploração de um fazendeiro, recebendo como pagamento do trabalho honesto um salário indigno e incerto, além de um teto. Fabiano, responsável por tratar diretamente com o dono do lugar em que estão abrigados, trabalha no cuidado dos animais, enquanto sua mulher, sinha Vitória, cuida da casa, dos filhos e da manutenção do que pode passar despercebido para seu marido. Não se trata de um trabalho visando ao lucro: não há acúmulo ou ganho, apenas luta pela sobrevivência. Diante disso, percebemos a presença de uma "violência estrutural" de que Fabiano e sua gente são vítimas, aponta para 0 que Minayo bem resume:

Diz respeito [A violência estrutural] às mais diferentes formas de manutenção das desigualdades sociais, culturais, de gênero, etárias e étnicas que produzem a miséria, a fome, e as várias formas de submissão e exploração de umas pessoas pelas outras. Mais cruel, é a violência que mantém a miséria de grande parte da população do país. Todos os autores que estudam o fenômeno da miséria e da desigualdade social mostram que sua naturalização o torna o chão de 
onde brotam várias outras formas de relação violenta (MINAYO, 2007, p. 12).

Porta de entrada para outras manifestações de força, a violência estrutural é a base das demais injustiças vividas pela família ficcionalizada por Graciliano. Estarem tão vulneráveis à fome e ao desabrigo os torna presas fáceis de abusos, a exemplo do que ocorre hoje, com as mudanças nas relações de trabalho que deixam a população mais frágil e desprotegida. Sem ter quem os defenda e sem alternativas, a família de Fabiano é roubada pelo dono das terras em que trabalham. Fabiano, na dependência do fazendeiro, sabe que não se trata de escolha receber menos do que deveria:

\begin{abstract}
Sinha Vitória fazia contas direito: sentava-se na cozinha, consultava montes de sementes de várias espécies, correspondentes a mil réis, tostões e vinténs. E acertava. As contas do patrão eram diferentes, arranjadas a tinta e contra o vaqueiro, mas Fabiano sabia que elas estavam erradas e o patrão queria enganá-lo. Enganava. Que remédio? Fabiano, um desgraçado, um cabra, dormia na cadeia e aguentava zinco no lombo. Podia reagir? Não podia. Um cabra. Mas as contas de Sinha Vitória deviam ser exatas (RAMOS, 2013, p. 114).
\end{abstract}

A violência estrutural é uma janela em que se descortinam outras formas de violência, não apenas no que diz respeito à relação entre "patrões x empregados", mas também quanto ao acesso daqueles sujeitos à educação. Segundo a Declaração Universal dos Direitos Humanos, a oportunidade de crescimento intelectual por meio das instituições de ensino é um direito de todos. No artigo XXVI, consta: "Todo ser humano tem direito à instrução. A instrução será gratuita, pelo menos nos graus elementares e fundamentais. A instrução elementar será obrigatória. A instrução técnico-profissional será acessível a todos, bem como a instrução superior, esta baseada no mérito" (DUDH, 1948). Contudo, diante da necessidade de se buscar o mínimo para a sobrevivência, as personagens de Graciliano Ramos expressam o cotidiano comum ao de muitos brasileiros sem acesso ao ensino, pois o trabalho se impõe emergencialmente. Resta para sinha Vitória e Fabiano sonharem com um futuro para seus filhos, que "mudar-seiam depois para uma cidade, e os meninos frequentariam escolas, seriam diferentes deles" (RAMOS, 2013, p. 127). 
A questão da educação, mais especificamente sua falta, é outro agravante da violência estrutural, pois acentua a vulnerabilidade dos sujeitos diante das estruturas hierárquicas e arbitrárias. É sabido que a sociedade da promessa moderna deveria alçar os homens a um estado de bem-estar social, no entanto, a corrupção social, moral, política e de toda ordem -, a manutenção de privilégios e a vigência de um capitalismo perverso são formas do mal estrutural que perpassa as épocas históricas e se manifestam como cânceres no seio de uma sociedade que se pretende justa: - poder quase sempre atua com violência para manter intocadas determinadas estruturas. $E$ isso não tem a ver com a competência ou mérito dos indivíduos.

Como afirma Adrian Sgarbin, em Teoria do direito (primeiras lições), o termo "competência" pode ter muitos sentidos. Dentre os três apontados pelo autor, o que nos interessa agora corresponde à terceira concepção, que vem a ser: "atribuição normativa de alguém" (SGARBIN, 2007, p. 56). Competência, nesse sentido, é a responsabilidade e a capacidade profissional de uma pessoa. Podemos afirmar, assim, que o uso de uma atribuição para suprimir o direito do outro constitui violência, de modo que, convém ressaltar, se a vítima da violência não tem consciência da violação a que está submetida, sua situação é ainda mais injusta, agravada pela ignorância frente a seus direitos subtraídos.

Já aludimos anteriormente a um exemplo de abuso policial no trato com o ignorante Fabiano. Retomemos e recordemos alguns outros momentos da passagem, dada a sua importância em nosso trabalho. Após perder seu pouco dinheiro em uma partida de cartas com o soldado da cidade, Fabiano é rechaçado e humilhado pelo policial, que 0 ofende e humilha, criando pretextos para prendê-lo:

- Vossemecê não tem direito de provocar os que estão quietos.

- Desafasta, bradou o polícia.

E insultou Fabiano, porque ele tinha deixado a bodega sem se despedir.

- Lorota, gaguejou o matuto. Eu tenho culpa de vossemecê esbagaçar os seus possuídos no jogo?

Engasgou-se. A autoridade rondou por ali um instante, desejosa de puxar questão. Não achando pretexto, avizinhou-se e plantou o salto da reiúna em cima da alpercata do vaqueiro.

- Isso não se faz, moço, protestou Fabiano. Estou quieto. Veja que mole e quente é pé de gente.

O outro continuou a pisar com força. Fabiano impacientou-se e xingou a mãe dele. Aí o amarelo apitou, e em 
poucos minutos o destacamento da cidade rodeava o jatobá.

- Toca pra frente, berrou o cabo. Fabiano marchou desorientado, entrou na cadeia, ouviu sem compreender uma acusação medonha e não se defendeu (RAMOS, 2013, p. 30-31).

A postura autoritária do "soldado amarelo" se firma na certeza de que Fabiano não saberia se defender e nem teria aliados poderosos. Assim, valendo-se de sua posição hierárquica como representante de um poder, de uma força fardada (o que potencializa sua situação de "autoridade" frente ao retirante inculto), o soldado incorpora a violência institucional e isso lhe dá o "direito" de submeter Fabiano a uma noite no cárcere, pelo prazer do exercício da força. Mais do que dominar o corpo do homem, a violência atua também sobre o seu intelecto. Em seus estudos sobre o poder e a violência, Michel Foucault apontou para a mudança do alvo punitivo por parte das instituições. Se na era medieval, os castigos visavam aos corpos, chegando à sua destruição, na era moderna o poder não se concentra exclusivamente no extermínio dos corpos, mas sim, em sua "domesticação". Dessa forma, não se pune apenas o corpo físico dos sujeitos: há novos objetos de coerção, como a mente (Foucault chama de a "alma"; Levinas classifica de "espírito"). Nos dirá Foucault:

Se não é mais ao corpo que se dirige a punição, em suas formas mais duras, sobre o que, então, se exerce? A resposta dos teóricos daqueles que abriram, por volta de 1780, o período que ainda não se encerrou - é simples, quase evidente. Dir-se-ia inscrita na própria indagação. Pois não é mais o corpo, é a alma. À expiação que tripudia sobre o corpo deve suceder um castigo que atue, profundamente, sobre o coração, o intelecto, a vontade, as disposições (FOUCAULT, 1987, s/p).

Em Vidas secas, é possível observar os modos como Fabiano internaliza as hierarquias sociais que 0 oprimem. Passado o episódio da prisão,por puro capricho do "soldado amarelo", Fabiano tem a chance de vingar-se, mas não o faz. Ao voltar para casa, já longe da cidade e de seus movimentos, Fabiano depara o soldado, perdido e sozinho. Inicialmente, passado o medo de nova injustiça, Fabiano recorda o vivido:

Tinha medo e repetia que estava em perigo, mas isto lhe pareceu tão absurdo que se pôs a rir. Medo daquilo? Nunca vira uma pessoa tremer assim. Cachorro. Ele não era dunga na cidade? Não pisava os pés dos matutos, na feira? Não botava gente na cadeia? Sem-vergonha, mofino (RAMOS, 2013, p. 103). 
Ponderadas as consequências de um ato de força seu, Fabiano submete-se ao soldado por entendê-lo como autoridade. Mesmo sendo mais forte fisicamente, o sertanejo não ousa desobedecer ao "governo":

\begin{abstract}
Afastou-se, inquieto. Vendo-o acanalhado e ordeiro, o soldado ganhou coragem, avançou, pisou firme, perguntou o caminho. $\mathrm{E}$ Fabiano tirou o chapéu de couro.

- Governo é governo.

Tirou o chapéu de couro, curvou-se e ensinou o caminho ao soldado amarelo (RAMOS, 2013, p. 107).
\end{abstract}

Esse poder que rege, não pela força, mas mediante o convencimento, Pierre Bourdieu chama de "Poder simbólico". Uma vez que não se tem a intenção de matar os subjugados, mas sim de persuadi-los a uma obediência que os dociliza, Bourdieu aponta para o modo como o "consenso" atua enquanto instrumento vital do poder simbólico, visando à "concordância das inteligências", ou seja, à manipulação do pensamento de uns em prol do de outros:

É enquanto instrumentos estruturados e estruturantes de comunicação e de conhecimento que os «sistemas simbólicos» cumprem a sua função política de instrumentos de imposição ou de legitimação de dominação, que contribuem para assegurar a dominação de uma classe sobre outra (violência simbólica) dando o reforço da sua própria força às relações de força que as fundamentam e contribuindo assim, segundo a expressão de Weber, para a «domesticação dos dominados» (BOURDIEU, 2012, p. 11).

\section{A postura de Fabiano é} estruturada e estruturante: ocorre por conta dos mecanismos de poder que o coloca abaixo do soldado, mas, simultaneamente, é o que reforça a atuação do agente que demanda obediência. Afinal, sem ter quem Ihes obedeça, as lideranças perdem seu poder. Igualmente, convém expor que Fabiano é alvo de imposições, mas também é ele quem exerce sua parcela de poder, no caso, com a seus filhos e à esposa, alvos de outra manifestação dos poderes simbólicos. É Fabiano quem impõe medo às crianças, bem como quem dá a palavra final sobre como gastar o salário, tal como fez ao perdê-lo no jogo, diante do soldado amarelo. Nesse prisma, constata-se que o poder simbólico não possui rosto definido, é poroso e pervasivo, infiltrando-se nas instâncias sociais e articulando-se em múltiplas direções: o oprimido pode passar a agressor e vice-versa; as diferenças podem anular-se ou assumir novos papéis, algumas se normatizando; desigualdades podem recrudescer ou 
acabar, dando lugar a outras formas hierárquicas de assimetrias.

Consequentemente, concepção do que vem a ser a realidade reflete as complexidades do mundo simbólico: "O poder simbólico é um poder de construção da realidade que tende a estabelecer uma ordem gnoseológica [...]" (BOURDIEU, 2012, p. 09). Por não serem relações naturais, determinadas por fatores biológicos ou imanentes aos humanos, as relações de poder fantasiam verdades que favorecem uns e prejudicam outros. Não sem razão, Bourdieu afirma ser, então, o "senso" apenas um "consenso" que modula a realidade:

"senso=consenso"(BOURDIEU, 2012, p. 09).

Observar a ficcionalização da realidade é algo tornado possível pela literatura e no romance de Ramos salta aos olhos a autopercepção de Fabiano. Ao não se reconhecer como sujeito de direito a uma humanidade que o torne verdadeiramente "homem" livre e porque internaliza as relações de força e segregação impostas a ele, Fabiano se define como "bicho". Mesmo sendo um homem, a forma desumana com que é levado a (sobre) viver leva-o a construir sobre si uma identidade atravessada por um poder simbólico em conformidade com os elementos da violência estrutural. Orgulhoso de ter encontrado, no início da narrativa, um lugar para ficar e se abrigar do sol "sanguíneo", junto de sua família, Fabiano sente-se exitoso e não se poupa em verbalizar sua felicidade, chamando a si de "homem". Porém, a realidade, tal como se apresenta, gera nele vergonha pelo dito, 0 que 0 faz modificar 0 substantivo usado para qualificar-se:

- Fabiano, você é um homem,
exclamou em voz alta.
Conteve-se, notou que os meninos
estavam perto, com certeza iam
admirar-se ouvindo-o falar só. E,
pensando bem, ele não era homem:
era apenas um cabra ocupado em
guardar coisas dos outros. Vermelho,
queimado, tinha os olhos azuis, a
barba e os cabelos ruivos; mas como
vivia em terra alheia, cuidava de
animais alheios, descobria-se,
encolhia-se na presença dos brancos
e julgava-se cabra.
Olhou em torno, com receio de que,
fora os meninos, alguém tivesse
percebido a frase imprudente.
Corrigiu-a, murmurando:
- Você é um bicho, Fabiano.
Isto para ele era motivo de orgulho.
Sim senhor, um bicho, capaz de
vencer dificuldades.

Há ainda que se pensar em outra manifestação de violência presente em Vidas secas. A falta de um teto e o acesso negado à educação são frutos daquela realidade 
árida em que falta do básico ao supérfluo, sempre uma falta que barra a possibilidade de uma vida digna. Ao que parece, para além dos bens e progresso materiais, a miséria e suas consequências roubam também 0 exercício aprofundado das faculdades comunicativas. A língua, como bem afirma Giorgio Agamben, é também um dispositivo:

\begin{abstract}
Não somente, portanto, as prisões, os manicômios, o Panóptico, as escolas, a confissão, as fábricas, as disciplinas, as medidas jurídicas etc., cuja conexão com o poder é num certo sentido evidente, mas também a caneta, as escrituras, a literatura, a filosofia, a agricultura, o cigarro, a navegação, os computadores, os telefones celulares e - por que não a própria linguagem, que talvez é o mais antigo dos dispositivos [...] (AGAMBEN, 2009, pg. 40-41).
\end{abstract}

Por meio de seu uso, o ser humano consegue se impor na ordem do mundo, conforme este se apresente. Não dominar a língua é estar em vulnerabilidade constante; sem a capacidade de exigir, argumentar, expressar-se, defenderse, entre outras insubstituíveis ações sociais, o homem passa a ser um joguete nas mãos dos que detêm os mecanismos de linguagem (leia-se, poder).

A família de sinha Vitória e Fabiano demonstra seu despreparo no uso das palavras, do qual possuem certa consciência de sua importância, visto que admiram a personagem Seu Tomás da Bolandeira justamente pelo uso efetivo da palavra - que, no entanto, não o salva da seca: "Seu Tomás fugira também, com a seca, a bolandeira estava parada. E ele, Fabiano, era como a bolandeira. Não sabia por que, mas era" (RAMOS, 2013, p. 15). Em outra passagem, vemos Fabiano como um sujeito que "na verdade falava pouco. Admirava as palavras compridas e difíceis da gente da cidade, tentava reproduzir algumas, em vão, mas sabia que elas eram inúteis e talvez perigosas" (RAMOS, 2013, p. 20). Esse domínio não proficiente no uso e na compreensão das palavras revela na leitura da obra uma série de relações produtivas. Uma delas possui raízes na psique humana.

Tentando driblar certo senso comum da crítica, não defenderemos a animalização como uma explicação única para as relações que se desenrolam no seio daquela família e nem nas relações desta com o mundo social. $\mathrm{O}$ emudecimento das personagens, ao que nos parece, pode ser compreendido de forma mais 
produtiva como uma reação humana frente à desumanidade que as cerca, por um lado; por outro, a falta de uma linguagem apreendida e depreendida de uma relação mais formal com as palavras e as limitações na interpretação do mundo sugerem uma crítica social contundente por parte de Ramos aos próprios mecanismos de uma sociedade de exclusão da qual ele participou como intelectual, escritor, político e vítima. Como intelectual e escritor, Ramos colocou seu trabalho a serviço de uma reflexão literária que não se demitiu jamais da crítica às estruturas de mundo opressivas e segregadoras; como político, exerceu na prática a atividade de administrador, quando se tornou prefeito eleito de Palmeiras dos Índios, em 1927; e como vítima de um regime de força e opressão, amargou a prisão em 1936, no Instituto Penal Cândido Mendes, na Ilha Grande, acusado, sem provas e inquérito, de participação na Intentona Comunista de 1935. Assim, apontamos que as personagens, pobres de linguagem e, consequentemente de mundo, são criações filosófico-literárias de um escritor que se preocupou com a dimensão humana e política de seu tempo.

Walter Benjamin, no ensaio "Experiência e pobreza" (1994), sinaliza para a emergência de uma escassez de experiências comunicáveis na modernidade. A comunicação, entendida até então como o poder de narrar, vê-se em crise, como no caso dos soldados sobreviventes da Primeira Guerra Mundial, que retornavam para suas localidades mudos de relatos. Quanto a isso, Benjamin produz as seguintes reflexões:

Os livros de guerra que inundaram o mercado literário nos dez anos seguintes não continham experiências transmissíveis de boca em boca. Não, o fenômeno não é estranho. Porque nunca houve experiências mais radicalmente desmoralizadas que a experiência estratégica pela guerra de trincheiras, a experiência econômica pela inflação, a experiência do corpo pela fome, a experiência moral pelos governantes (BENJAMIN, 1994, p. 115).

Mesmo com histórias a contar, oficiais sobreviventes da guerra não conseguiam verbalizar suas vivências. Isso não se deu porque se tornaram sujeitos animalizados ou porque perderam sua capacidade de falar, mas sim por conta de uma "ferida na memória”, conforme Márcio 


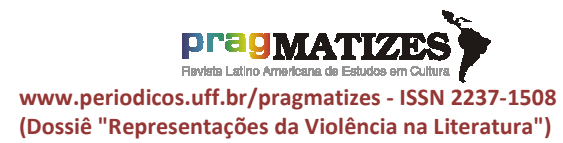

Seligmann-Silva define o trauma, gravada durante o tempo de luta nos campos de batalha e nas trincheiras. $\mathrm{O}$ trauma diante do evento catastrófico da guerra acabou por emudecer os soldados. Para Benjamin, isso revela a pobreza da experiência de um mundo em que os atos de fala estão sendo silenciados por conta de um acontecimento que ultrapassa a possibilidade de contar: a experiência da dizimação em massa.

Pensar o trauma no romance de Ramos requer relativizar e/ou ir além da categórica classificação das personagens principais como seres zoomorfizados. As sucessivas secas e o drama histórico dos retirantes são da ordem do trauma, mas não do mesmo tipo que Benjamin apontara em sua incursão pela pobreza dos relatos de experiências dos soldados retornados da guerra. Seligmann-Silva entende a experiência traumática como "um dos conceitos-chave da psicanálise", e o tratamento psicanalítico - resumido o pensamento de Seligmann - existe em função do trabalho de recomposição do evento traumático. O que é 0 trauma? "O trauma é justamente uma ferida na memória" (SELIGMANNSILVA. 2000. p. 84).
Fabiano e sua família chegam à fazenda em que grande parte da narrativa se passa após vaguearem famintos, fracos e sedentos ("a experiência do corpo pela fome"), sem a certeza de que encontrariam refúgio. Se para os oficiais foi a guerra que provocou a mudez e a pobreza dos relatos, para as personagens de Vidas secas é possível entender a seca como um fenômeno de um meio em que se dá o evento traumático que vitima um conjunto de indivíduos: o trauma atravessa a fala desses seres e aprofunda a ferida da memória de que trata Seligmann.

No tempo presente da obra, a seca é, em grande parte da narrativa, passado, habitando o universo das memórias traumáticas; ou futuro, assombrando as possibilidades de vida por vir. Em um dos poucos momentos em que a seca é experimentada no presente da narrativa, encontramos sinha Vitória refletindo sobre um evento doloroso:a necessidade de matar um dos animais de estimação da família para alimentar a família, o papagaio, mudo, assim como todos ali eram:

Sinha Vitória, queimando o assento no chão, as mãos cruzadas segurando os joelhos ossudos, 
pensava em acontecimentos antigos que não se relacionavam: festas de casamento, vaquejadas, novenas, tudo numa confusão. Despertara-a um grito áspero, vira de perto a realidade e o papagaio, que andava furioso, com os pés apalhetados, numa atitude ridícula. Resolvera de supetão aproveitá-lo como alimento e justificara-se declarando a si mesma que ele era mudo e inútil. Não podia deixar de ser mudo.. Ordinariamente a família falava pouco. E depois daquele desastre viviam todos calados, raramente soltavam palavras curtas. O louro aboiava, tangendo um gado inexistente, e latia arremedando a cachorra (RAMOS, 2013, p. 11-12).

É possível ver na superfície do texto o modo como a seca e seus desdobramentos afetaram a fala de todas as personagens: " $E$ depois daquele desastre viviam todos calados, raramente soltavam palavras curtas". O sol ardente que enxugava do barro toda água também secou da família a linguagem. Embora tendo o que dizer uns aos outros, o conteúdo a ser dito, dada sua carga dolorosa, evidenciou a pobreza de diálogos e não o seu enriquecimento diante da experiência traumática da morte do animal de estimação. Entretanto, o que não é dito é pensado. Por meio do narrador, o leitor de Vidas secas tem acesso às reflexões das personagens e pode atestar que de seus pensamentos podemos detectar construções lógicas, lembranças complexas e desejos profundos. É por este viés que compreendemos o jogo narrativo de Ramos: mediação entre a possibilidade do narrador de se expressar com mais propriedade do que qualquer uma das personagens e a incapacidade de cada uma das criaturas retirantes de dar conta, pelo relato, daqueles eventos traumáticos por que passam. Esta mediação entre o narrador e o leitor é necessária, pois o leitor poderia apontar uma falha no critério da verossimilhança, caso a fala dos quatro membros da família não fosse negociada por um narrador que a princípio tem o dom de traduzir um pouco do que a linguagem precária das personagens não teria como expressar.

Como seres expostos à violência traumática de uma existência de seca, exílios e privações, Fabiano, sinha Vitória, o menino mais novo e o menino mais velho têm algo em comum com as vítimas do Holocausto. A tensão constante entre vida e morte na obra, acessível pela análise da desumana forma de vida a que estão submetidos os retirantes, permite que sejam feitas aproximações entre Shoah e sertão nordestino brasileiro, 
embora saibamos que 0 evento catastrófico do Holocausto judeu é incomparável como potencialidade da barbárie.

Diante de uma vida seca, mísera e cujas memórias traumáticas remetem ao medo, tais como fantasmas que povoam as mentes e assombram os futuros, como poderiam Fabiano e sinha Vitória expressar a potência de sua humanidade? Diante de um futuro incerto, tendo nos ombros a responsabilidade de alimentar e proteger os filhos, que tipo de linguagem poderiam ter aqueles entes marcados pelo sol sanguíneo e pelas últimas viagens sobre o chão rachado do agreste? Algumas palavras de Seligmann-Silva apontam para as impossibilidades de se retratar as experiências vividas pelos traumatizados da Shoah:

O historiador da Shoah fica preso a
esse duplo mandamento
contraditório: por um lado, a
necessidade de escrever sobre esse
evento, e, por outro lado, a
consciência da impossibilidade de
cumprir essa tarefa por falta de um
aparato conceitual "à altura" do
evento, ou seja, sob o qual ele
poderia ser subsumido
(SELIGMANN-SILVA, 2000, p. 78).

Como vemos, o problema em Vidas secas possui similaridades com a observação de Seligmann, mas o drama das personagens é de outra natureza: Em Vidas secas, não haveria outra possibilidade de se escrever sobre o trauma vivido, a não ser como faz Ramos, ao criar um narrador heterodiegético que pode dar conta daquele universo traumático sem ferir de morte as regras da verossimilhança, que de outra forma deixariam a obra em estado de fragilidade em uma leitura mais atenta. O problema dos sobreviventes da Shoah, em sua grande maioria, era da ordem da dor de exprimir o inexprimível e da vergonha por terem sobrevivido, enquanto parentes e amigos pereceram diante da barbárie.

Talvez, ciente dessa limitação intransponível que vem a ser a representação do trauma de modo integral, Graciliano Ramos tenha optado por um narrador não personagem, ou seja, alguém que trate da dor como fruto da violência que outros viveram, sem a preocupação com a exatidão do relato, visto que a memória é sempre falha, ou com os sentimentos perturbadores de quem passou pela experiência de um sofrimento atroz. É justamente nessa tentativa de se construir um "cercamento em torno dos sem- 


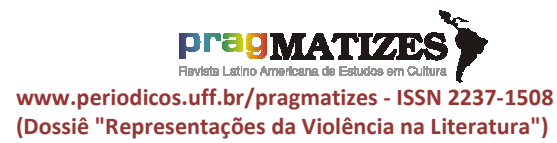

palavras", como bem afirma Paul Celan, que a obra poética se torna uma forma de tratar dos sobreviventes da Shoah (Cf. SELIGMANN-SILVA, 2000, p. 97). É com dificuldade que uma vítima do trauma consegue relatar os fatos vividos. Torna-se necessário ao passo que também é incontornável -, ao que parece, um determinado afastamento do fato. Para Celan, tal distanciamento na representação do trauma é uma estratégia da arte. Em Vidas Secas, a escolha por um determinado tipo de narrador figura essa aproximação distanciada: enquanto terceira pessoa do discurso (muito embora tal definição não seja absoluta e não nos pareça a mais adequada), ouvimos, através do narrador, as personagens; mas elas não estão no pleno uso das palavras, visto que são tuteladas, como vimos anteriormente, por essa instância narrativa que as precede.

Em suma, emudecida pela dor e presa das muitas formas de violência, a família que protagoniza Vidas secas permite que problematizemos os efeitos da violência na psique humana. Seria esse, então, o trabalho da escuta, próprio da psicanálise. Sob o imperativo de um mundo que os ultrapassa e subjuga, definir Fabiano e sua família como humanos animalizados pode sugerir outra forma de violência: simbólica e crítico-teórica.

Se entendermos que nestes sujeitos reside também a capacidade de não revidar, de considerar o não assassinato, de relevar a agressão sofrida - mesmo que isso se dê sob o peso de um respeito ou medo em relação a uma ordem superior e a um poder invisível, quer seja o da Lei, do Estado, da Polícia - esses sujeitos do perdão se aproximam do excelso e se enredam em uma ordem de que os demais - o fazendeiro, o soldado amarelo, a polícia, o governo etc. - se excluem, por incapacidade de seus espíritos cultos e letrados de vencerem as iniquidades de que se revestem. Fabiano e sua família podem ser lidos como seres exemplares no sentido dos espíritos que, como vimos com Levinas (2016, p. 65), nos obrigam a olhar de forma crítica para uma sociedade "que perde o contato vivo com seu verdadeiro ideal de liberdade para aceitar suas formas degeneradas e que, não vendo que esse ideal exige esforço, rejubila-se, sobretudo com o que ele traz de comodidade [...]". Eles se tornam, deste modo, mais próximos 
de uma ideia de caritas, solidariedade

e compartilhamento, elementos que faltam à sociedade descrita pelo narrador de Vidas secas, como um todo. Daí a grandeza de Fabiano e dos seus.

Tal como Benjamin expusera, a incapacidade de falar é resultado das experiências empobrecedoras e traumáticas, como bem apontou Seligmann-Silva. O silêncio, deste modo, pode ser lido como o máximo de concentração de diversas falas ou ainda, como um silêncio que grita: por socorro, pela atenção aos sujeitos enclausurados e a seus corpos subjugados.

\section{Referências bibliográficas}

AGAMBEN, Giorgio. $O$ que é dispositivo? In: $O$ que é contemporâneo? e outros ensaios. Trad. Vinícius Nicastro Honesko. Chapecó, SC: Argos, 2009.

BATAILLE, Georges. Nietzsche e os fascistas; Proposições. Acéphale, n. 2, Florianópolis, p. 3-15; 19-23, 2013.

BENJAMIN, Walter. Experiência e Pobreza. In: Magia e técnica, arte e política: ensaios sobre literatura e história da cultura.Trad. Sergio Paulo Rouanet. 7. ed. São Paulo: Brasiliense, 1994 (Obras escolhidas, V. I).

BOURDIEU, Pierre. O poder simbólico. Trad. Fernando Tomaz. 16 ed. Rio de Janeiro: Bertrand Brasil, 2012.
CANDIDO, Antonio. Ficção e confissão: ensaios sobre Graciliano Ramos. 3 ed. Rio de Janeiro: Ouro Sobre Azul, 2006.

CARVALHO, Castelar de. Ensaios gracilianos. Rio de Janeiro: Editora Rio, 1978. p. 15-29.

DAVIDSON, Arnold I.; LENINAS, Emmanuel; MUSIL, Robert. 19331934: Reflexões sobre o Nacionalsocialismo. In: Reflexões sobre 0 Nacional-socialismo. Belo Horizonte: Âyiné, 2016, p. 11-43.

DAVIDSON, Arnold I.; LENINAS, Emmanuel; MUSIL, Robert. Reflexões sobre o Nacional-socialismo. Belo Horizonte: Âyiné, 2016.

DECLARAÇÃO UNIVERSAL DOS DIREITOS HUMANOS. Assembleia Geral das Nações Unidas em Paris. 10 dez. 1948. Disponível em: https://www.ohchr.org/EN/UDHR/Page s/Language.aspx? LangID=por.

FOUCAULT, M. Vigiar e punir: nascimento da prisão. Trad. Raquel Ramalhete. Petrópolis, RJ: Vozes, 1987.

LEVINAS, Emmanuel. Algumas reflexões sobre a filosofia do hitlerismo. In: DAVIDSON, Arnold I.; LENINAS, Emmanuel; MUSIL, Robert. Reflexões sobre o Nacionalsocialismo. Belo Horizonte: Âyiné, 2016. p. 45-67.

MINAYO, Maria Cecília S. Conceitos, teorias e tipologias da violência: a violência faz mal a saúde. In: NJAINE, K., ASSIS, S. G, CONSTANTINO, P. Impactos da violência na saúde [online]. Rio de Janeiro: Editora FIOCRUZ, 2007.

MITCHELL, W. J. T. Critical inquiry. Chicago: University of Chicago Press, n. 1, v. 17, Autumn 1990. 
RAMOS, Graciliano. Vidas secas. 121. ed. Posfácio Hermenegildo Bastos. Rio de Janeiro: Record, 2013.

REBELLO, IIma da Silva. As classes populares e as duras cavalgaduras da vida: uma leitura de Vidas secas, de Graciliano Ramos. Soletras, n. 10, São Gonçalo, RJ, Universidade do Estado do Rio de Janeiro, p. 85-96, , jul./dez.2005.

SELIGMANN-SILVA, Márcio. A história como trauma. In: _.. (org.). Catástrofe e representação. São Paulo: Escuta, 2000.

SGARBIN, Adrian. Teoria do direito (primeiras lições). Rio de Janeiro: Lumen Juris, 2007.

SPIVAK, Gayatri Chakravorty. Pode o subalterno falar? Trad. Sandra Regina Goulart de Almeida; Marcos Pereira Feitosa; André Pereira Feitosa. Belo Horizonte: Editora UFMG, 2010. 